\title{
Pengetahuan Lokal dan Keanekaragaman Tumbuhan Berguna Pada Masyarakat Batulanteh, Pulau Sumbawa, Nusa Tenggara Barat: Sebuah Kajian Etnobotani
}

\author{
Mulyati Rahayu \\ Nissa Arifa \\ Muhamad Nikmatullah \\ Ary Prihardhyanto Keim
}

Email korespondensi

\author{
Kelompok Penelitian Etnobiologi, Pusat Penelitian Biologi, \\ Lembaga Ilmu Pengetahuan Indonesia \\ Kelompok Penelitian Etnobiologi, Pusat Penelitian Biologi, \\ Lembaga Ilmu Pengetahuan Indonesia \\ Kelompok Penelitian Etnobiologi, Pusat Penelitian Biologi, \\ Lembaga Ilmu Pengetahuan Indonesia \\ Kelompok Penelitian Etnobiologi, Pusat Penelitian Biologi, \\ Lembaga Ilmu Pengetahuan Indonesia
}

mulyati_r@yahoo.com

\begin{abstract}
The study was conducted in Batulanteh District, Sumbawa regency, Sumbawa Island, West Nusa Tenggara, which is aimed to reveal the knowledge of the Samawa people on the diversity of useful plants and their uses. It documented 111 plant species, in which $47.5 \%$ are used as traditional medicine. Also, the sudy found that wild honey bees (Apis dorsata) is having a conspicuous association with plants in producing natural honey, which plays an important role in the local economy. The interviews with selected respondents showed that the Samawa people totally understand the importance of forest conservation in relation with the existence of the honey bees' life.
\end{abstract}

Keywords: Batulanteh, ethnobotany, Samawa, Sumbawa, useful plants

\section{PENDAHULUAN}

Pulau Sumbawa merupakan salah satu pulau dalam gugusan Kepulauan Nusa Tenggara. Berbeda dengan dua pulau di sebelah baratnya, Lombok dan Bali, keanekaragaman jenis tumbuhan di pulau ini belum banyak dikenal. Kawasan pegunungan Batulanteh merupakan salah satu kawasan konservasi di Kabupaten Sumbawa Besar dengan ketingggian berkisar antara $500-1800 \mathrm{~m}$ dpl dan dengan kemiringan medan antara $40-80^{\circ}$. Keberadaan kawasan hutan ini sangat penting karena selain sebagai hulu dari Daerah Aliran Sungai (DAS) untuk mensuplai air bagi Kota Sumbawa, juga merupakan habitat lebah madu liar penghasil utama madu Sumbawa.

Masyarakat Samawa Batulanteh sangat menghargai kekayaan jenis tumbuhannya dan menempatkannya dalam kedudukan yang penting terkait perikehidupan mereka sehari-hari. Banyak jenis-jenis tumbuhan berperawakan pohon yang meski tidak dimanfaatkan secara langsung oleh mereka namun tetap dijaga kelestariannya karena pohon-pohon tersebut berfungsi sebagai rumah bagi lebah madu liar (Apis dorsata) yang mereka panen madunya dan justru menjadi salah satu komoditas yang membuat Desa Batulanteh dikenal bahkan 
hingga ke luar Sumbawa. Hutan Batulanteh memang diketahui merupakan sumber madu terbesar di Sumbawa baik dari sisi volume perdagangan maupun jumlah pemburu madu yang terlibat dalam industri ini (Julmansyah, 2008).

Dalam kaitannya dengan jenis-jenis tumbuhan berguna masyarakat Samawa mempunyai pengetahuan yang baik. Masyarakat Samawa umumnya telah sejak lama hidup dari usaha pertanian dengan bercocok tanam padi di ladang atau berkebun kopi dan kemiri. Lingkungan tempat tinggal masyarakat Samawa merupakan lingkungan budidaya yang mencakup pekarangan, tegalan dan perkebunan. Rensch (1930) dan Kostermans (1963) adalah dua rujukan yang paling kerap digunakan untuk keanekaragaman hayati tumbuhan Pulau Sumbawa. Lebih sedikit dari itu adalah informasi seputar kajian etnobotaninya, dan terkait itulah penelitian ini dilakukan. Kajian ini termasuk yang awal dilakukan, maka diharapkan dapat memberikan landasan kuat bagi pemanfaatannya, termasuk bioprospecting.

\section{METODE}

\section{Lokasi Penelitian}

Lokasi penelitian dipusatkan di kawasan Batulanteh, yang merupakan salah satu dari 24 Kecamatan di Kabupaten Sumbawa, Propinsi Nusa Tenggara Barat (Gambar 1). Terdapat 10 desa yang termasuk ke dalam wilayah Kecamatan Batulanteh, yaitu Batudulang, Baturontok, Baudesa, Kaduk, Musuk, Pusu, Riu, Sukamaju, Tangkepkulit, dan Tepal. Terkait dengan kemiringan medan, semua desa di atas, kecuali Batudulang. Mayoritas penduduknya berasal dari suku Samawa dan beragama Islam. Mata pencaharian utama mereka adalah bertani kopi robusta (Coffea canephora), kopi arabika (Coffea arabica), kemiri (Aleurites moluccana), dan madu yang dihasilkan lebah madu hutan (Apisdorsata). Kopi robusta dan kemiri merupakan dua jenis tanaman budidaya pendatang. Rata-rata tiap kepala keluarga memiliki 50 pohon kemiri dan 100 pohon kopi robusta.

\section{Pengumpulan dan Analisis Data}

Pengumpulan data dilakukan dengan menggunakan metode Walk in the Wood (Cunnigham, 2001; Hoang et al., 2008) yaitu berupa wawancara dan pengamatan langsung di lapangan. Informan kunci yang digunakan adalah anggota masyarakat yang mampu memberikan informasi yang akurat yaitu yang memiliki pengetahuan yang baik tentang keanekaragaman jenis tumbuhan berguna, di mana setiap jenis tumbuhan berguna dicatat nama lokalnya dan kegunaannya. Pengambilan sampel dalam bentuk spesimen herbarium. Identifikasi dilakukan di Herbarium Bogoriense (BO). Data etnobotani yang berhasil didokumentasikan dianalisis dengan pendekatan kualitatif dan menyajikannya dalam bentuk tabel dan gambar. 


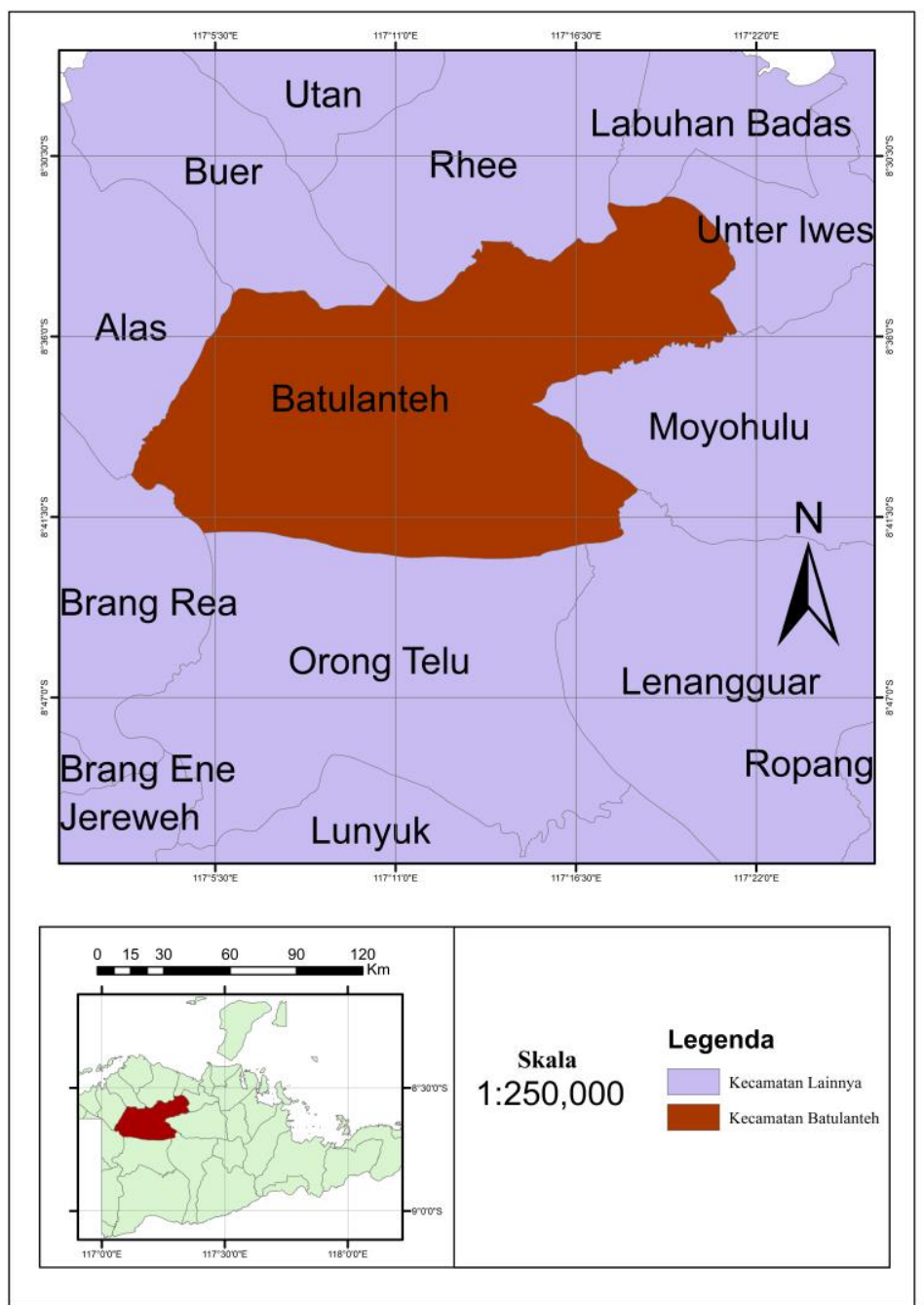

Gambar 1. Kawasan Batulanteh, Sumbawa, Nusa Tenggara Barat

\section{HASIL DAN PEMBAHASAN}

\section{Pengetahuan Masyarakat Samawa Terhadap Keanekaragaman Tumbuhan}

Masyarakat di Batulanteh merupakan masyarakat petani yang tinggal dengan kawasan hutan, mereka mempunyai ketergantungan yang tinggi terhadap hutan. Hasil penelitian menunjukkan bahwa masyarakat Samawa di Batulanteh mengetahui 111 pengetahuan tentang keanekaragaman jenis tumbuhan, terutama untuk aneka jenis tumbuhan yang dimanfaatkan dalam kehidupan sehari-hari, seperti sumber bahan pangan, obat, bahan bangunan, kayu bakar, pakan ternak peliharaan, dan tempat bersarangnya lebah penghasil madu. Sebaliknya, jenis-jenis tumbuhan liar yang jarang atau tidak dimanfaatkan umumnya tidak dikenal secara baik antara lain Aphanamixis polystachya, Begonia spp., Elatostema sp., Knema laurina, Piper spp., Phyllanthus emblica, Pothos sp. dan Freycinetia spp., yang secara umum disebut 'klipan' dan sebenarnya terdiri dari dua jenis: $F$. insignis dan $F$. sumbawaensis (Keim dan Rahayu, 2010). 'Pade' atau padi (Oryza sativa) merupakan jenis tanaman yang mempunyai nilai paling penting diantara jenis-jenis tanaman penghasil karbohidrat lainnya. Meski begitu, tidak banyak anggota masyarakat Samawa di Batulanteh yang bercocok tanam padi dan ini 
berkaitan dengan topografi Batulanteh yang berbukit-bukit dengan sedikit areal lahan datar yang cocok untuk persawahan. Oleh kareana itu hasil panen padi selalu disimpan dalam 'alang' lumbung yang bentuk dan struktur bangunannya tidak berubah semenjak jaman leluhur mereka.
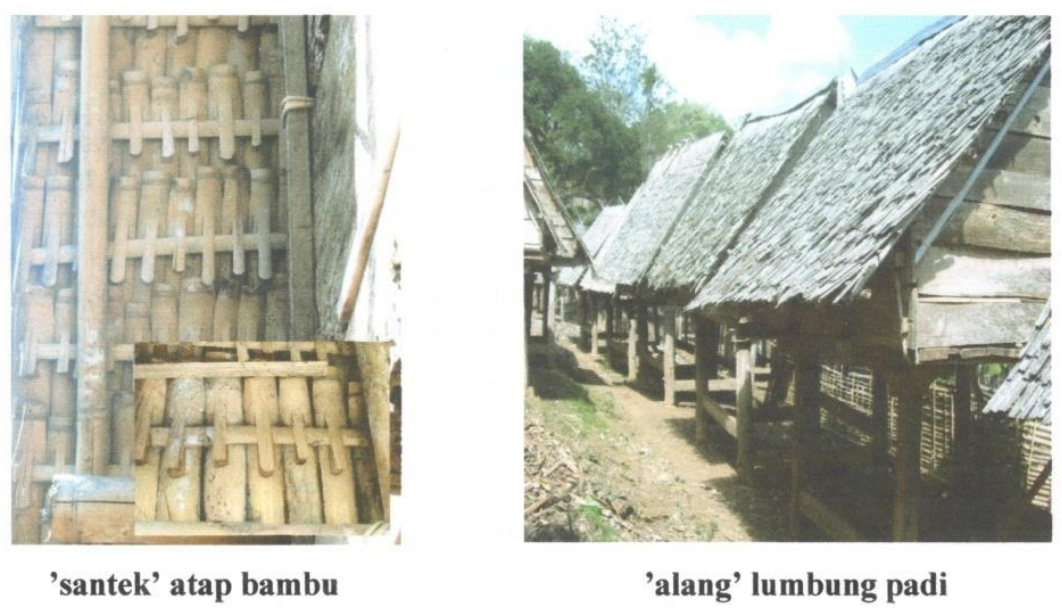

Gambar 2. Bentuk dan struktur bangunan tempat menyimpan hasil panen padi

Tegalan umumnya ditanami dengan 'kitabang' atau ubi kayu (Manihot esculenta), 'baso' atau jagung (Zea mays), dan 'nyir' atau nyiur (Cocos nucifera). Penanaman ke tiga jenis ini dilakukan bersamaan saat pembukaan tegalan, dan pemanenan dilakukan bertahap yaitu panen jagung ( 3 - 4 bulan), kemudian ubi kayu (8 - 9 bulan). Penanaman ke dua jenis ini (jagung dan ubi kayu) untuk menjaga ketersediaan bahan pangan (karbohidrat) sebagai pengganti beras.

Pekarangan rumah umumnya ditanami sayuran dan buah-buahan seperti bayam (Amaranthus hibridus), cabe (Capsicum fructescens), terung (Solanum melongena), nanas (Ananas comosus), 'nyamung' atau 'jambu biji' (Psidium guajava), dan 'nyamung ae' atau jambu air (Syzygium aqueum). Aneka jenis tanaman hias juga ditanam di pekarangan antara lain 'puring' (Codieum variegatum) dan 'hanjuang' (Cordyline fruticosa), dan umumnya ditanam sebagai tanaman pagar atau pembatas. Hal ini diduga berkaitan dengan warna daunnya yang kurang lazim (tidak hijau), hal tersebut didukung oleh Heyne (1987) yang menyebutkan hanjuang sebagai tanaman terminalis atau perdu batas.

Bentuk bangunan asli sebagai tempat tinggal masyarakat Samawa, sebagaimana halnya hampir seluruh tipe asli rumah bangsa besar Austronesia adalah berupa rumah panggung kayu dengan dinding dari anyaman bambu dan beratapkan 'santek'. 'Santek' dibuat dari seruas batang bambu 'treng' atau 'ae' yang dibelah dua kemudian dibelah lagi dibagian tengah lalu disusun seperti sirap. Sayangnya saat ini atap 'santek' telah banyak ditinggalkan karena pengerjaannya membutuhkan waktu yang lama dan penguasaan teknik yang rumit. Dengan kata lain, efek negatif dari pragmastism telah mendorong masyarakat Samawa untuk meninggalkan tradisi tersebut. Meski begitu, untungnya hingga saat ini atap 'santek' masih dapat dijumpai pada bangunan-bangunan lumbung padi atau dalam bahasa Samawa disebut 'alang'. Fenomena ini dapat ditafsirkan bahwa padi memiliki nilai yang sangat tinggi di masyarakat Samawa sebagaimana layaknya bangsa besar Austronesia lainnya yang dari Madagaskar di barat hingga Pulau Paskah di timur, dan dari Taiwan di utara hingga Selandia Baru di selatan (Blench, 2008; Donohue dan Denham, 2010; Pearce dan Pearce, 
2010). Diharapkan bahwa dengan terus ditempatkannya pada dalam kedudukan yang penting, setidaknya secara kultural, 'santek' akan terjaga kelestariannya.

Tabel 1. Tumbuhan Berguna dan Pemanfaatannya di Batulanteh, Sumbawa

\begin{tabular}{|c|c|c|c|c|}
\hline No. & Nama Ilmiah & Suku & Nama Lokal & Kegunaan \\
\hline 1 & $\begin{array}{l}\text { Abelmoschus } \\
\text { esculentus }\end{array}$ & Malvaceae & Jamia & $\begin{array}{l}\text { Buah dimakan bagai bahan } \\
\text { sayuran }\end{array}$ \\
\hline 2 & Agave sisalana & Asparagaceae & Panan ring & Penangkal setan \\
\hline 3 & Aleurites moluccanus & Euphorbiaceae & Miri & $\begin{array}{l}\text { Kulit kayu obat paska } \\
\text { persalinan; bunga pakan } \\
\text { lebah madu; biji komoditi } \\
\text { perdagangan; kayu bakar }\end{array}$ \\
\hline 4 & Aloe vera & Xanthorrhoeaceae & Sekir baya & $\begin{array}{c}\text { Daun perangsang ASI, } \\
\text { pengganti shampoo }\end{array}$ \\
\hline 5 & Alstonia scholaris & Apocynaceae & Lita & $\begin{array}{l}\text { Kulit kayu obat paska } \\
\text { persalinan, obat batuk darah, } \\
\text { penurun panas; Pohon 'boan' }\end{array}$ \\
\hline 6 & $\begin{array}{c}\text { Elettaria } \\
\text { cardamomum }\end{array}$ & Zingiberaceae & Kapulaga & $\begin{array}{c}\text { Biji campuran 'rampagenap'; } \\
\text { bumbu }\end{array}$ \\
\hline 7 & Etlingera heyneana & Zingiberaceae & Goal & $\begin{array}{l}\text { Bunga pakan lebah; buah } \\
\text { untuk memandikan jenasah }\end{array}$ \\
\hline 8 & Areca catechu & Arecaceae & Pinang & $\begin{array}{c}\text { Akar obat kuat untuk laki- } \\
\text { laki }\end{array}$ \\
\hline 9 & Averrhoa bilimbi & Oxalidaceae & Binang & $\begin{array}{c}\text { Daun campuran 'repusit'; } \\
\text { buah untuk sambal }\end{array}$ \\
\hline 10 & $\begin{array}{l}\text { Barringtonia } \\
\text { racemose }\end{array}$ & Lecythidaceae & Putat & Kulit kayu pewarna merah \\
\hline 11 & Bischofia javanica & Phyllanthaceae & Lintung & Kulit kayu campuran 'songa' \\
\hline 12 & Blumea balsamifera & Compositae & Kesemung & $\begin{array}{l}\text { Daun obat paska persalinan; } \\
\text { bunga pakan lebah madu }\end{array}$ \\
\hline 13 & Blumea chinensis & Compositae & Kemusi & $\begin{array}{l}\text { Bunga obat lidah putih pada } \\
\text { balita }\end{array}$ \\
\hline 14 & Caesalpinia bonduc & Leguminosae & Marugi & Biji obat diabetes \\
\hline 15 & Caesalpinia sappan & Leguminosae & Sepang & $\begin{array}{l}\text { Kulit kayu untuk pencegah } \\
\text { pendarahan }\end{array}$ \\
\hline 16 & Caesalpinia sp. & Leguminosae & Aru & Daun muda untuk 'sepat' \\
\hline 17 & Calotropis gigantea & Apocynaceae & Mariga & $\begin{array}{l}\text { Getah obat sakit gigi; bunga } \\
\text { pakan lebah }\end{array}$ \\
\hline 18 & Chilocarpus sp. & Apocynaceae & Pulasari & $\begin{array}{c}\text { Bunga pewangi pakaian, akar } \\
\text { bahan campuran bedak }\end{array}$ \\
\hline 19 & $\begin{array}{l}\text { Cinnamomum } \\
\text { burmanni }\end{array}$ & Lauraceae & Kayu manis & $\begin{array}{l}\text { Biji campuran 'rampagenap'; } \\
\text { kulit kayu bahan rempah }\end{array}$ \\
\hline 20 & Cinnamomum iners & Lauraceae & Kayu lawang & Kulit kayu obat pening \\
\hline 21 & Citrus aurantiifolia & Rutaceae & Limo lawas & $\begin{array}{c}\text { Akar obat pegal linu, } \\
\text { Buah penghilang bau anyir } \\
\text { ikan }\end{array}$ \\
\hline 22 & Clematis sp. & Ranunculaceae & Lonto kasipit & Batang pengganti tali \\
\hline 23 & Cocos nucifera & Arecaceae & Nyir & Akar obat kuat laki laki; buah \\
\hline
\end{tabular}




\begin{tabular}{|c|c|c|c|c|}
\hline & & & & $\begin{array}{l}\text { komoditi perdagangan; bunga } \\
\text { pakan lebah; tangkai daun } \\
\text { kayu bakar; batang bahan } \\
\text { bangunan. }\end{array}$ \\
\hline 24 & Coriandrum sativum & Apiaceae & Ketumbar & $\begin{array}{l}\text { Biji campuran 'rampagenap', } \\
\text { bumbu }\end{array}$ \\
\hline 25 & Crescentia cujete & Bignoniaceae & Maja & $\begin{array}{c}\text { Tanaman pagar, bunga pakan } \\
\text { lebah }\end{array}$ \\
\hline 26 & $\begin{array}{c}\text { Maclura } \\
\text { cochinchinenchis }\end{array}$ & Moraceae & Galiaga & Kulit kayu pewarna kuning \\
\hline 27 & Curcuma longa & Zingiberaceae & Kunyit & Umbi obat balita agar sehat \\
\hline 28 & $\begin{array}{c}\text { Cyathea } \\
\text { contaminans }\end{array}$ & Cyatheaceae & Pakis treng & Batang bahan kerajinan \\
\hline 29 & Derris trifoliata & Leguminosae & Kenekal & $\begin{array}{l}\text { Bunga pakan lebah; batang } \\
\text { campuran obat kuat }\end{array}$ \\
\hline 30 & Dioscorea spp. & Dioscoreaceae & Egal & Umbi bahan pangan \\
\hline 31 & Dipterocarpus sp. & Dipterocarpaceae & Prek mayung & $\begin{array}{l}\text { Batang bahan bangunan, } \\
\text { Pohon 'boan' }\end{array}$ \\
\hline 32 & Lablab purpureus & Leguminosae & Komak & Buah bahan pangan \\
\hline 33 & $\begin{array}{l}\text { Duabanga } \\
\text { moluccana }\end{array}$ & Lythraceae & Kayu rimas & $\begin{array}{l}\text { Bunga pakan lebah; kayu } \\
\text { bahan bangunan; Pohon } \\
\text { 'boan' }\end{array}$ \\
\hline 34 & Dysoxylum sp. & Meliaceae & Kayu tahi & $\begin{array}{l}\text { Buah pakan monyet; kayu } \\
\text { bahan bakar }\end{array}$ \\
\hline 35 & $\begin{array}{c}\text { Elatostema } \\
\text { macrophyllum }\end{array}$ & Urticaceae & Telat & Pucuk daun untuk sayur \\
\hline 36 & $\begin{array}{c}\text { Erythrina } \\
\text { subumbrans }\end{array}$ & Leguminosae & Rupe & $\begin{array}{l}\text { Tanaman pagar, pelindung } \\
\text { kopi, bunga pakan lebah }\end{array}$ \\
\hline 37 & $\begin{array}{l}\text { Austroeupatorium } \\
\text { inulaefolium }\end{array}$ & Compositae & Santalo & Bunga pakan lebah \\
\hline 38 & Euodia sp. & Rutaceae & Mpang & Bunga pakan lebah \\
\hline 39 & $\begin{array}{l}\text { Exocarpos } \\
\text { longifolius } \\
\end{array}$ & Santalaceae & Belida & $\begin{array}{l}\text { Batang untuk tongkat, } \\
\text { penangkal setan }\end{array}$ \\
\hline 40 & Ficus racemosa & Moraceae & Ara & $\begin{array}{l}\text { Buah dimakan; pohon } \\
\text { 'panalu' }\end{array}$ \\
\hline 41 & Ficus sp. & Moraceae & Poso & Daun muda dimakan \\
\hline 42 & Ficus fistulosa & Moraceae & Suir & $\begin{array}{c}\text { Kulit kayu obat kuat, obat } \\
\text { pegal-pegal, obat sakit } \\
\text { pinggang }\end{array}$ \\
\hline 43 & $\begin{array}{l}\text { Flemingia } \\
\text { strobilifera }\end{array}$ & Leguminosae & Sarenggang & Bunga pengganti kapuk \\
\hline 44 & Alyxia pilosa & Apocynaceae & Kayu batu & $\begin{array}{l}\text { Kulit kayu untuk 'salapang' } \\
\text { KB }\end{array}$ \\
\hline 45 & Glochidion sp. & Phyllanthaceae & $\begin{array}{c}\text { Kayu } \\
\text { ceremai }\end{array}$ & Buah dimakan \\
\hline 46 & Gossypium arboreum & Malvaceae & $\begin{array}{l}\text { Kapas } \\
\text { mayung }\end{array}$ & Kapas \\
\hline
\end{tabular}




\begin{tabular}{|c|c|c|c|c|}
\hline 47 & $\begin{array}{l}\text { Graptophyllum } \\
\text { pictum }\end{array}$ & Acanthaceae & Sate ati & $\begin{array}{l}\text { Daun untuk memperlancar } \\
\text { urine, penurun panas; akar } \\
\text { obat nafsu makan }\end{array}$ \\
\hline 48 & $\begin{array}{l}\text { Hydrocotyle } \\
\text { sibthorpioides }\end{array}$ & Araliaceae & Bebele & $\begin{array}{c}\text { Daun obat sakit kepala, obat } \\
\text { keputihan, obat bau mulut, } \\
\text { obat pegal-pegal }\end{array}$ \\
\hline 49 & Jatropha curcas & Euphorbiaceae & Jarak pagar & $\begin{array}{l}\text { Tanaman pagar; getah obat } \\
\text { sakit perut; daun obat } \\
\text { kembung; kulit kayu obat } \\
\text { agar balita sehat }\end{array}$ \\
\hline 50 & Lantana camara & Verbenaceae & $\begin{array}{c}\text { Sang } \\
\text { mamung }\end{array}$ & $\begin{array}{l}\text { Bunga pakan lebah, kayu } \\
\text { bakar }\end{array}$ \\
\hline 51 & Lawsonia inermis & Lythraceae & Pancar & Daun pewarna kuku \\
\hline 52 & Leea aequata & Vitaceae & Kayu rante & $\begin{array}{l}\text { Daun dan buah penyubur } \\
\text { padi (magik) }\end{array}$ \\
\hline 53 & Limonia acidissima & Rutaceae & Ganista & Buah dimakan; kayu bakar \\
\hline 54 & Litsea accedentoides & Lauraceae & $\mathrm{Udu}$ & $\begin{array}{l}\text { Bunga pakan lebah; buah } \\
\text { pakan monyet; pohon } \\
\text { 'panalu' }\end{array}$ \\
\hline 55 & Litsea tomentosa & Lauraceae & Kayu ela & Kulit kayu campuran 'songa' \\
\hline 56 & Maesa perlaria & Primulaceae & $\begin{array}{l}\text { Grengromon } \\
\mathrm{g}\end{array}$ & Buah dimakan \\
\hline 57 & Mallotus sp. & Euphorbiaceae & Oma & $\begin{array}{c}\text { Daun muda dan buah } \\
\text { dimakan; buah obat cacing } \\
\text { dan panu }\end{array}$ \\
\hline 58 & Mangifera spp. & Anacardiaceae & Po & Buah dimakan \\
\hline 59 & $\begin{array}{c}\text { Melastoma } \\
\text { malabathricum }\end{array}$ & Melastomaceae & Beso & $\begin{array}{c}\text { Buah dimakan, pewarna biru; } \\
\text { bunga pakan lebah }\end{array}$ \\
\hline 60 & Melia azedarach & Meliaceae & Mindi & Daun obat diabetes \\
\hline 61 & Melochia umbellata & Malvaceae & Lentenu & $\begin{array}{l}\text { Batang kayu bakar; pohon } \\
\text { 'panalu' }\end{array}$ \\
\hline 62 & Mesona sp. & Lamiaceae & Rebu kepal & Bunga pakan lebah \\
\hline 63 & $\begin{array}{l}\text { Michecarpus } \\
\text { sundaicus }\end{array}$ & Sapindaceae & Kayu minyak & $\begin{array}{l}\text { Batang bahan bangunan, } \\
\text { kayu bakar; pohon 'boan' }\end{array}$ \\
\hline 64 & Mimosa pudica & Leguminosae & Sarat & Bunga pakan lebah \\
\hline 65 & $\begin{array}{c}\text { Momordica } \\
\text { charantia }\end{array}$ & Cucurbitaceae & Paria & $\begin{array}{c}\text { Daun dan buah } \\
\text { memperbanyak ASI }\end{array}$ \\
\hline 66 & Moringa oleifera & Moringaceae & Kele & $\begin{array}{c}\text { Daun memperbanyak ASI, } \\
\text { obat sakit perut }\end{array}$ \\
\hline 67 & Nicotiana tabaccum & Solanaceae & Mako & Daun bahan rokok \\
\hline 68 & $\begin{array}{l}\text { Palaquium } \\
\text { obtusifolium }\end{array}$ & Sapotaceae & Semelu & $\begin{array}{l}\text { Daun muda dimakan; kulit } \\
\text { batang obat paska persalinan; } \\
\text { batang gagang parang; pohon } \\
\text { 'boan' }\end{array}$ \\
\hline 69 & $\begin{array}{c}\text { Pandanus } \\
\text { amaryllifolius }\end{array}$ & Pandanaceae & $\begin{array}{c}\text { Pandan } \\
\text { wangi }\end{array}$ & Daun pewangi masakan \\
\hline 70 & Pandanus faviger & Pandanaceae & Pandan layun & $\begin{array}{l}\text { Ujung akar gantung obat kuat } \\
\text { laki-laki }\end{array}$ \\
\hline
\end{tabular}




\begin{tabular}{|c|c|c|c|c|}
\hline 71 & Pandanus tectorius & Pandanaceae & Pandang & $\begin{array}{l}\text { Daun untuk memandikan } \\
\text { jenasah }\end{array}$ \\
\hline 72 & Pandanus tectorius & Pandanaceae & Panan ring & Daun bahan anyaman \\
\hline 73 & Peperomia pellucida & Piperaceae & Kedesan & $\begin{array}{l}\text { Semua bagian Obat pegal- } \\
\text { pegal }\end{array}$ \\
\hline 74 & Phyllanthus acidus & Phyllanthaceae & Ceremai & Daun campuran 'repusit' \\
\hline 75 & Phyllanthus emblica & Phyllanthaceae & Malaka & $\begin{array}{c}\text { Buah dimakan; daun pewarna } \\
\text { hijau }\end{array}$ \\
\hline 76 & Piper betle & Piperaceae & Eta & $\begin{array}{c}\text { Daun campuran } \\
\text { 'rampagenap', obat tetes } \\
\text { mata, sirih pinang, penangkal } \\
\text { setan }\end{array}$ \\
\hline 77 & Piper nigrum & Piperaceae & Sang & $\begin{array}{l}\text { Biji campuran 'rampagenap', } \\
\text { komoditi perdagangan }\end{array}$ \\
\hline 78 & Piper retrofractum & Piperaceae & Cabe ulet & $\begin{array}{l}\text { Buah campuran } \\
\text { 'rampagenap' }\end{array}$ \\
\hline 79 & Piper sarmentosum & Piperaceae & Kaduk & $\begin{array}{c}\text { Daun penurun panas, obat } \\
\text { sesak nafas }\end{array}$ \\
\hline 80 & Planchonia valida & Lecythidaceae & Belinat & $\begin{array}{l}\text { Bunga pakan lebah; pohon } \\
\text { 'boan' }\end{array}$ \\
\hline 81 & $\begin{array}{l}\text { Plectranthus } \\
\text { amboinicus }\end{array}$ & Lamiaceae & Poko & $\begin{array}{l}\text { Daun untuk mencegah } \\
\text { payudara bengkak }\end{array}$ \\
\hline 82 & $\begin{array}{l}\text { Pogonatherum } \\
\text { paniceum }\end{array}$ & Poaceae & & Pakan ternak sapi \\
\hline 83 & Protium javanicum & Burseraceae & Ketimis & Daun muda untuk 'sepat' \\
\hline 84 & Pterocarpus indicus & Leguminosae & $\begin{array}{l}\text { Kemang } \\
\text { kuning }\end{array}$ & $\begin{array}{c}\text { Bunga pakan lebah; kayu } \\
\text { bahan bangunan }\end{array}$ \\
\hline 85 & Rubus rosifolius & Rosaceae & Kesisik & Buah dimakan \\
\hline 86 & Sapindus rarak & Sapindaceae & Suat & $\begin{array}{c}\text { Bunga pakan lebah; buah } \\
\text { pengganti sabun; pohon } \\
\text { 'boan' }\end{array}$ \\
\hline 87 & Schleichera oleosa & Sapindaceae & Kesaming & Batang penangkal setan \\
\hline 88 & Schoutenia ovata & Tiliaceae & Kukim & $\begin{array}{l}\text { Bunga pakan lebah; pohon } \\
\text { 'panalu' }\end{array}$ \\
\hline 89 & Solanum torvum & Solanaceae & $\begin{array}{l}\text { Katemung } \\
\text { sengit }\end{array}$ & $\begin{array}{c}\text { Akar penurun panas; buah } \\
\text { dimakan }\end{array}$ \\
\hline 90 & Spilanthes acmella & Compositae & Malat & $\begin{array}{l}\text { Bunga pakan lebah; daun anti } \\
\text { racun belut }\end{array}$ \\
\hline 91 & Spondias sp. & Anacardiaceae & Kuhinu & $\begin{array}{l}\text { Bunga pakan lebah; pohon } \\
\text { 'panalu' }\end{array}$ \\
\hline 92 & $\begin{array}{l}\text { Syzygium } \\
\text { aromaticum }\end{array}$ & Myrtaceae & Cengkeh & $\begin{array}{l}\text { Biji campuran 'rampagenap'; } \\
\text { komoditi perdagangan }\end{array}$ \\
\hline 93 & $\begin{array}{c}\text { Syzygium } \\
\text { polyanthum }\end{array}$ & Myrtaceae & Doat & $\begin{array}{l}\text { Bunga pakan lebah; pohon } \\
\text { 'boan' }\end{array}$ \\
\hline 94 & $\begin{array}{l}\text { Tabernaemontana } \\
\text { macrocarpa }\end{array}$ & Apocynaceae & Peko salaki & $\begin{array}{c}\text { Kulit kayu obat paska } \\
\text { persalinan }\end{array}$ \\
\hline 95 & Talinum javanicum & Portulacaceae & Gingseng & $\begin{array}{l}\text { Semua bagian obat sakit } \\
\text { pinggang }\end{array}$ \\
\hline
\end{tabular}


Journal of Tropical Ethnobiology Vol.3 No.1 (2020): 28-42

Rahayu dkk. Pengetahuan lokal dan keanekaragaman tumbuhan ...

\begin{tabular}{|c|c|c|c|c|}
\hline 96 & Tetrameles nudiflora & Tetramelaceae & Binong & $\begin{array}{l}\text { Kulit kayu pewarna hitam; } \\
\text { pohon 'boan' }\end{array}$ \\
\hline 97 & Toddalia sp. & Rutaceae & $\begin{array}{c}\text { Kayu } \\
\text { berabuk }\end{array}$ & Daun obat pegal-pegal \\
\hline 98 & Toona sureni & Meliaceae & Suran & Bahan bangunan \\
\hline 99 & Trichosanthes sp. & Cucurbitaceae & $\begin{array}{l}\text { Temuruk } \\
\text { gamang }\end{array}$ & Biji obat demam \\
\hline 100 & Zingiber officinale & Zingiberaceae & $\mathrm{Je}$ & $\begin{array}{l}\text { Umbi campuran 'songga', } \\
\text { bumbu }\end{array}$ \\
\hline 101 & Zingiber montanum & Zingiberaceae & Bangle & Umbi obat agar balita sehat \\
\hline 102 & Alocasia sp. & Araceae & Bia & Bunga pakan lebah \\
\hline 103 & & Asteraceae & Kenunung & Bunga pakan lebah \\
\hline 104 & & Moraceae & Pelas & $\begin{array}{c}\text { Daun pengganti sikat gigi; } \\
\text { kulit kayu obat perawatan } \\
\text { paska persalinan }\end{array}$ \\
\hline 105 & & & $\begin{array}{l}\text { Akar pelas } \\
\text { ode }\end{array}$ & $\begin{array}{c}\text { Semua bagian untuk } \\
\text { merapatkan vagina }\end{array}$ \\
\hline 106 & Aganosma wallichii & Apocynaceae & Jeliti & $\begin{array}{l}\text { Kulit kayu obat perawatan } \\
\text { paska persalinan; daun untuk } \\
\text { mencegah bayi masuk angin }\end{array}$ \\
\hline 107 & Glinus oppositifolius & Molluginaceae & Jemari & $\begin{array}{c}\text { Daun obat perawatan paska } \\
\text { persalinan }\end{array}$ \\
\hline 108 & Pisonia umbellifera & Nyctaginaceae & Kayu kalong & Kulit kayu supaya bayi kuat \\
\hline 109 & & & Kayu puin & Bunga pakan lebah \\
\hline 110 & & & Kayu teleh & Bunga pakan lebah \\
\hline 111 & Portulaca oleracea & Portulacaceae & Ngalir & $\begin{array}{c}\text { Daun untuk mempercepat } \\
\text { proses kelahiran }\end{array}$ \\
\hline
\end{tabular}

Meskipun letak desa-desa di Kecamatan Batulanteh tergolong cukup jauh dari ibukota Kecamatan Semongkat dan sarana jalan kurang baik, masyarakat lokal tidak menemui kendala berarti dalam pemenuhan kebutuhan energi untuk keperluan sehari-hari seperti memasak, karena mereka mengenal dengan baik jenis-jenis tumbuhan sumber kayu bakar berkualitas (daya bakar tinggi dan awet) seperti 'kayu tahi' (Dysoxylum sp.), 'lentenu' (Melochia umbilata) dan 'kayu minyak' (Lithocarpus sundaica). Terlepas dari kebutuhan akan sumber bahan bakar yang selalu ada, masyarakat Samawa mempunyai kearifan lokal untuk tidak melakukan penebangan secara sembarang karena mereka mengkhawatirkan terganggunya kelangsungan hidup lebah madu liar (Apis dorsata) yang kerap ditemukan bersarang di batang-batang jenis-jenis pohon tersebut. Umumnya untuk memenuhi kebutuhan kayu bakar sehari-hari mereka mengambilnya dari patahan-patahan dahan, ranting atau batang dari jenis-jenis tanaman budidaya seperti kelapa, kemiri, kopi robusta, dan mangga.

Masyarakat Samawa saat ini tidak mengenal banyak jenis tumbuhan pangan sayuran dan buah-buahan. Nampaknya ini disebabkan generasi yang ada saat ini banyak menerima warisan lahan dari pendahulu mereka, umumnya berupa kebun kopi dan kemiri. Ragam sayuran tradisional yang masih dapat dijumpai antara lain 'sepat', yaitu campuran antara daun muda 'ketimis' (Protium javanicum), 'aru' (Caesalpinia aff. pulcherrima), dan buah muda 'kapuk randu' (Ceiba pentandra) yang diolah dengan bumbu berupa cabai, 'ruku-ruku' (Ocimum basilicum), dan 'lemo asam' (Citrofortunella microcarpa). 'Sepat' biasanya dihidangkan bersama dengan ikan laut. Tradisi makan 'sepat' biasanya dilakukan selama 
bulan suci Ramadhan (puasa). 'Ketimis' dan 'aru' diperdagangkan di pasar-pasar tradisional, meski begitu ke dua jenis tumbuhan tersebut tidak dibudidaya dan didapatkan dengan mengambil dari hidupan liar.

Darnaedi dan Rodani (1995) melaporkan bahwa di beberapa desa di kawasan barat daya Sumbawa kayu 'ketimis' dan 'aru' juga digunakan dalam ramuan obat untuk perawatan pasca melahirkan. Hasil penelitian ini menunjukkan bahwa penggunaan kayu dari ke dua jenis tumbuhan tersebut tidak dikenal oleh masyarakat Samawa di Batulanteh. Buah 'ganista' (Limonia acidissima) merupakan salah satu jenis buah-buahan yang diperdagangkan di pasarpasar tradisional. Sepanjang pengamatan yang dilakukan dalam penelitian ini, jenis tumbuhan tersebut belum dibudidaya. Di daratan Asia Tenggara duri dan kulit batang tumbuhan ini digunakan dalam banyak ramuan obat tradisional untuk menghentikan pendarahan berlebihan dalam menstruasi (haid), gangguan hati, gigitan atau sengatan binatang serta menghilangkan mual (Jones, 1997). Walaupun telah mengalami pengikisan akibat pengaruh penggunaan obat-obatan sintetis, namun pengetahuan akan obat-obatan tradisional masih terjaga dengan baik, terutama dalam perawatan paska melahirkan, di mana digunakan beberapa jenis tumbuhan terutama 'lita' (Alstonia scholaris). Jenis ini tumbuhan ini termasuk ke dalam daftar tumbuhan langka Indonesia (Mogea, dkk., 2001). Hal ini diyakini karena lokasi desadesa di Batulanteh saling berjauhan dan sulitnya transportasi untuk menuju Balai Kesehatan atau Puskesmas yang terletak di ibukota kecamatan.

Suku Sasak di Pulau Lombok memang dikenal memiliki pengetahuan pengobatan tradisional yang disebut 'isi kantong' yang diketahui terdiri dari 40 macam simplisia (Rahayu, dkk., 2002). Sementara masyarakat Samawa di Batulanteh, meski masih dikategorikan secara etnologis sebagai anggota etnis Sasak, menyebutnya sebagai 'rampa genap', 'repusit', dan 'songga' yaitu ramuan tumbuh-tumbuhan untuk perawatan pasca melahirkan. Kegunaan ramuan simplisia ini antara lain untuk memperlancar keluarnya darah kotor, memperlancar peredaran darah, memberi rasa hangat pada tubuh, mengembalikan kondisi rahim dan vagina seperti semula, mencegah sakit kepala, dan mempercepat pulihnya kebugaran.

Perbedaan lain diantara ke dua suku Sasak dan Samawa dalam kaitan dengan tumbuhan obat antara lain dalam kasus 'bebele'. Bagi masyarakat suku Sasak di desa Sembalum Lawang, Pulau Lombok tumbuhan dengan nama daerah 'bebele' merujuk kepada Centella asiatica dan digunakan sebagai obat penurun panas dan penyubur kandungan (Rahayu, dkk., 2002). Sementara masyarakat Samawa Batulanteh menyebut 'bebele' untuk jenis tumbuhan lain yang diidentifikasi sebagai Hydrocotyle sibthorpioides yang sepintas memang sangat mirip dengan $C$. asiatica, terutama dalam karakter morfologi bentuk daun. Hydrocotyle sibthorpioides oleh masyarakat Samawa digunakan sebagai obat sakit kepala, keputihan, bau mulut, dan pegal-pegal.

Masyarakat Samawa menggunakan akar penopang 'pandan layun' (Pandanus faviger) yang belum menyentuh tanah sebagai obat keperkasaan pria (Keim dan Rahayu, 2010). Pandanus faviger juga ditemukan di Jawa (sudah sangat langka) dan Bali, namun praktek tersebut tidak ditemukan. Cara penggunaannya adalah dengan merebus ujung akar tersebut terlebih dahulu dalam segelas air hingga volume air tinggal setengah gelas, lalu didiamkan hingga hangat untuk kemudian langsung diminum. Penganggapan dan penerimaan akar penopang pandan layun yang belum menyentuh tanah sebagai obat keperkasaan pria nampaknya mendukung teori 'doctrine of signature' (Licker, 2003; Trivedi dan Nehra, 2009), yang mana akar penopang yang masih menggantung tersebut melambangkan alat kelamin pria (penis) sehingga diyakini juga memiliki khaziat yang terkait dengan organ tersebut. Selain dari 'pandan layun' ( $P$. faviger), pemanfaatan jenis pandan lain oleh masyarakat 
Samawa untuk obat keperkasaan pria juga ditemukan, seperti penggunaan buah majemuk (cephalia) dari 'klipan' yang merujuk kepada Freycinetia insignis (Keim dan Rahayu 2010) yang sepintas mirip dengan alat kelamin pria.

Penelitian lebih lanjut di bidang bioprospecting layak dilakukan untuk kedua jenis tumbuhan di atas guna mengetahui apakah keduanya memang mengandung senyawa aktif yang berperan sebagai agen afrodisiak. Satu dari beberapa jenis tumbuhan obat yang digunakan oleh masyarakat Batulanteh ternyata termasuk ke dalam ragam jenis tumbuhan langka Indonesia yaitu 'lita' (Alstonia scholaris) dan digunakan sebagai obat penurun panas, malaria dan ramuan perawatan paska persalinan (Mogea, dkk., 2001). Exocarpos longifolius ditemukan pada ketinggian sekitar $1000 \mathrm{~m}$ dpl. Di Batulanteh jenis tumbuhan ini ditemukan hidup mengelompok, pada lahan-lahan terbuka dengan musim kering yang menonjol. Diameter batang kayunya tidak besar $( \pm 10 \mathrm{~cm})$ dan teksturnya keras. Jenis ini oleh masyarakat Samawa dikenal dengan nama "balida" atau "kayu Sulaiman". Kayunya tidak dimanfaatkan oleh masyarakat Samawa Batulanteh, tetapi oleh masyarakat di luar Batulanteh antara lain masyarakat Bali, umumnya dipergunakan sebagai bahan kebudayaan pada tempattempat suci agama Hindu, gagang keris dan tongkat komando, dan yang terkait magis sebagai penagkal setan.

Jenis-jenis tumbuhan yang digunakan oleh masyarakat Samawa untuk bahan baku kerajinan dan anyaman tidak banyak. Masyarakat Samawa mengenal nama lokal tumbuhan dengan sebutan 'panan ring' untuk dua jenis tumbuhan yang berbeda yaitu Agave sisalana dan Pandanus tectorius. Penelitian ini menduga bahwa nama 'panan ring' sebenarnya diberikan atau merujuk kepada $P$. tectorius, bukan untuk $A$. sisalana. Hal ini didasarkan atas asumsi:

1. Secara fitogeografi, A.sisalana adalah jenis tanaman pendatang yang aslinya berasal dari Amerika Tengah (terutama Meksiko). Dengan kata lain, A. sisalana bukan merupakan tumbuhan asli kawasan floristik Flora Malesiana. Kapan tepatnya jenis ini masuk ke Batulanteh tidak diketahui secara pasti karena baik Rensch (1930) maupun Kostermans (1963) tidak melaporkan kehadirannya. Kemungkinan besar tumbuhan ini masuk awalnya sebagai tanaman hias.

2. Secara morfologi, A. sisalana memiliki perawakan yang mirip dengan pandan, terutama marga Pandanus, sehingga diberi nama 'panan' sebagaimana layaknya untuk marga Pandanus (Keim dkk., 2013). Dengan kata lain, nama 'panan' merupakan sebuah variasi kata dari kata asli Bahasa Malayo - Austronesia, 'pandan'- karena memiliki kesamaan morfologi (terutama daun) dengan pandan asli Flora Malesiana (marga Pandanus), yang mana daunnya telah diketahui luas di Jawa dan kawasan sekitarnya sebagai bahan baku anyaman atau kerajinan tangan, terutama $P$. tectorius (Hofstede, 1925) atau $P$. faviger (Keim dan Rahayu, 2010).

3. Secara linguistik kata ring adalah berasal dari bahasa Belanda berarti cincin atau putaran merujuk kepada susunan daun rapat melingkar dalam putaran spiral. Perawakan yang juga dimiliki oleh sebagian besar anggota marga Pandanus, termasuk $P$. tectorius dan $P$. faviger terutama semasa tahapan anakan atau belum berbatang tegak.

Klasifikasi yang disusun oleh masyarakat tradisional seperti di atas bukanlah hal luar biasa karena kerap ditemukan di banyak masyarakat di banyak tempat di dunia (Berlin, 1992). Meski dalam hubungan kekerabatan klasifikasi tradisional dan ilmiah (filogenetik) kadang memiliki kesepadanan, namun dalam kaitan dengan pemanfaatan keduanya kerap bertolak belakang. Agave sisalana digunakan untuk keperluan mistis sebagai penangkal setan, sementara $P$. tectorius digunakan sebagai bahan baku anyaman tikar dan 'kelampi' 
yaitu wadah bekal nasi dalam berpergian. Menurut masyarakat setempat nasi yang disimpan dalam wadah tersebut akan berbau harum dan tidak mudah basi.

Pandanus tectorius ditemukan sebagai tumbuhan meliar yang hidup di belukar terbuka atau hutan sekunder. Jenis ini di Jawa digunakan sebagai bahan baku tikar, terutama di daerah Banten dan Jawa Barat yang dikenal dengan nama daerah 'pandan samak' (Hofstede, 1925) dan dibudidaya di banyak daerah seperti di Desa Cigundil, Banten (Rahayu, dkk., 2008) dan di daerah Tasikmalaya (Susiarti dan Rahayu, 2010). Selain ragam tumbuhan berbiji (Spermatophyta), tumbuhan paku (Pteridophyta) berukuran besar yaitu 'pakis treng' (Cyathea contaminans) juga digunakan sebagai bahan baku anyaman atau kerajinan. Jenis ini banyak dijumpai di lereng-lereng bukit sepanjang perjalanan dari Desa Batudulang menuju Desa Tepal. Masyarakat setempat menuturkan bahwa pada antara tahun 2007 hingga 2008 batang 'pakis treng' banyak diminati orang guna diperdagangkan sebagai bahan baku kerajinan di Bali. Sebagai dampaknya adalah eksploitasi besar-besaran. Untunglah kegiatan tersebut berangsur berkurang dan tidak sampai menghabiskan populasi yang ada.

\section{Industri Madu Alam}

Pengambilan madu alam telah dilakukan sejak lama oleh masyarakat Samawa Batulanteh terutama masyarakat pedesaan Batudulang dan Pusu. Rensch (1930) melaporkan usaha madu alam di kawasan Batulanteh, khususnya Batudulang dan Pusu, sebagai pusat industri tradisional madu alam Sumbawa. Bunga sebagai pakan lebah madu bersumber dari berbagai jenis tumbuhan yang terdapat di hutan hujan dataran rendah hingga pegunungan rendah Batulanteh seperti 'bentenu' (Duabanga moluccana), 'udu' (Litsea accentoides), 'doat' (Syzygium poliantha), 'kayu mpang' (Evodia sp.), 'santolo' (Eupatorium pallescens), 'kukuni' (Schoutenia ovata), 'kesambi' (Schleichera oleosa), dan beberapa jenis lain yang juga penting dalam kaitan dengan pakan lebah madu. Sedangkan bunga tanaman budidaya yang di sukai lebah madu antara lain jagung (Zea mays), 'po' (Mangifera indica), padi (Oryza sativa), kemiri (Aleurites moluccana), kopi robusta (Coffea robusta), dan 'rope' (Erythrina variegata). Terkait dengan pemanenan madu alam, masyarakat Samawa mengenal aturan adat berupa kepemilikan atas 'boan' dan 'panalu'. 'Boan' adalah pohon yang memiliki lebih dari satu sarang lebah madu alami; sementara 'panalu' merujuk kepada pohon yang memiliki satu sarang lebah. Orang pertama yang menemukan 'boan' atau 'panalu' di kawasan hutan liar yang tidak berpemilik maka, ia memiliki hak untuk memberi tanda kepemilikan atasnya dan dengan sendirinya berhak memanen madu alami tersebut. Namun apabila 'boan' atau 'panalu' tersebut berada di kebun atau lahan milik orang lain, maka pembagian hasil panen madu tergantung dari kesepakatan bersama yang diatur dengan hukum adat.

Praktek hukum adat yang sama dengan di atas juga ditemui di Jambi, di mana istilah yang sepadan dengan 'boan' adalah 'pohon selang' atau 'sialang', sementara 'panalu' sejajar dengan 'pohon bumbun' (Hariyadi, dkk., 2005; Susiarti, dkk., 2011). Praktek hukum adat yang kurang lebih sama juga ditemui di Kalimantan Barat, di mana dikenal istilah yang sepadan yaitu 'sompuat' dan 'lalau' (de Yong, 2000; Mulder, dkk., 2000; Heri dan Hermanto, 2009). Praktek hukum adat seperti di atas diyakini adalah 'temuan' asli bangsa besar Austronesia, setidaknya rumpun besar Malayo-Austronesia (i.e. West-Central Austronesians). Jenis-jenis pohon yang umumnya dimasukkan sebagai 'boan' adalah 'rimas' (yang diidentifikasi di sini sebagai jenis yang sama dengan 'bentenu' yaitu Duabanga moluccana, 'binong' (Tetrameles nudiflora), kemiri, 'suran' (Toona sureni), dan 'putat' (Barringtonia 
racemosa). Sementara untuk 'panalu' adalah Litsea accendetoides, Syzygium poliantha, dan 'nunu ara' (Ficus spp.).

Proses pengambilan dan pengolahan (pasca panen) madu alam dilakukan sepenuhnya secara tradisional dan telah diketahui turun temurun. Setiap pemburu madu harus dibekali pengetahuan tentang teknik memanjat yang baik (sehingga tidak merusak pepohonan di sekitarnya), menentukan hari dan waktu yang tepat untuk mengambil madu, dan cara mengusir lebah madu dari sarangnya. Tidak jarang pula para pemburu madu melibatkan bantuan 'sandro' atau 'tau Samawa' yaitu sebutan untuk tetua adat Samawa.

Peralatan panen madu alam cukup sederhana antara lain berupa 'rengke' yaitu semacam tangga, 'api poyong' untuk membuat asap guna mengusir lebah madu, 'api pontat' yaitu bara api yang dipakai untuk pemanenan di malam hari, 'rean' yaitu wadah untuk menampung madu (saat ini umumnya terbuat dari plastik), dan 'berang' yaitu parang untuk memangkas sarang lebah. Pemanenan madu umumnya dilakukan pada siang hari dengan cara mengambil bagian tertentu dari sarang lebah madu yang disebut 'pongong' dengan tujuan agar lebah madu dapat kembali bersarang pada tempat yang sama. Penirisan dilakukan dengan menggunakan pisau anti karat, kemudian disaring bertingkat guna mencegah madu tercemar oleh anak lebah atau serbuk sari (polen). Penyaringan umumnya dilakukan di kampung.

Petani madu di Batudulang mengatakan bahwa meski madu dihasilkan sepanjang tahun, namun bulan April, Juli, dan September merupakan bulan-bulan produksi madu yang tertinggi, sedangkan Januari dan Februari merupakan bulan-bulan dengan produksi madu yang terendah. Fenomena tersebut di duga di sini terkait dengan masa perbungaan (anthesis) sebagian besar tumbuhan berbunga yang menjadi sumber pakan lebah madu hutan. Kriteria madu bermutu tinggi antara lain berkadar air kurang dari $20 \%$ dan memiliki rasa serta aroma yang khas tergantung pada jenis tumbuhan dari mana pakan (nektar) lebah madu berasal.

\section{KESIMPULAN}

Masyarakat Samawa di Kecamatan Batulanteh menjaga keberadaan hutan sebagai bagian dari kehidupan mereka, terutama dalam kaitan dengan industri tradisional madu hutan. Jenis-jenis pohon yang umum dan penting dalam kaitan dengan industri madu tersebut dijaga dengan hukum adat dan umumnya termasuk ke dalam suku-suku Lauraceae, Lythraceae, Meliaceae, dan Myrtaceae. 'Kemiri', 'kopi robusta', dan madu hutan berperan penting dalam perekonomian masyarakat di Batulanteh.

\section{DAFTAR PUSTAKA}

Berlin, B. 1992. Ethnobiological classification: Principles of categorization of plants and animals in traditional societies. Princeton University Press, Princeton.

Blench, R. 2008. The Austronesians in Madagascar and their interaction with the Bantu of the East African Coast: Surveying the linguistic evidence for domestic and trans-located animals. Studies in Philippine Languages and Cultures 18: 18-43.

Cunningham, A.B. 2001. Applied ethnobotany: People, wild plant use \& conservation. Earthscan Publication, London. 
Darnaedi, S.Y., Rodani. 1995. Kearifan budaya dalam tradisi pengobatan orang Sumbawa Barat Daya, Nusa Tenggara Barat. Prosiding Seminar dan Lokakarya Nasional Etnobotani II, Yogyakarta, 29-38 p.

De Yong, W. 2000. Micro differences in local recourcea management: The case of honey in West Kalimantan, Indonesia. Human Ecology 28 (2): 631-639.

Donohue, M., Denham, T. 2010. Farming and language in island Southeast Asia. Current Anthropology 51 (2): 223-256.

Hariyadi, B., Subagio, A., Azra, R. 2005. Pelepat: traditional practice of wild honey harvesting. Journal of Tropical Ethnobiology 11 (2): 70-78.

Heyne K. 1987. Tumbuhan berguna Indonesia. Badan Litbang Departemen Kehutanan, Jakarta.

Heri, V., Hermanto. 2009. Bunga-bunga yang menjadi pakan lebah di Danau Sentarum, Kalimantan Barat. Alam Sumbawa 1 (April-Mei): 8-9.

Hoang, S.V., Baas, P., Kebler, J.A 2008. Use and conservation of plant species in national park: A case study of Ben In, Vietnam. Economic Botany 62(4): 574-593.

Hofstede, H.W. 1925. Het pandanblad: Als grondstof voor de pandanhoedenindustrie op Java. Eibergen: H, Heinen.

Jones, D.T. 1997. Limonia acidissima L. dalam Verheij, E.W.M., Coronel, R.E. (eds.). 1997. Buah-buahan yang dapat dimakan. PROSEA Sumber Daya Nabati Asia Tenggara 2, Gramedia Pustaka Utama, Jakarta.

Julmansyah. 2008. Sumbawa menjelang setengah abad. Pemerintah Kabupaten Sumbawa.

Keim, A.P., Rugayah, Rustiami, H. (eds.). 2013. Pandanaceae of Flora Malesiana in the past eight years (2005-2013): A state of the art. Herbarium Bogoriense, Bogor.

Keim, A.P., Rahayu, M. 2010. Pandanaceae of Sumbawa, West Nusa Tenggara, Indonesia. Reinwardtia 13(2): 151-158.

Kostermans, A.J.G.H. 1963. Notes on the vegetation of West Sumbawa (Indonesia). Symposium on the Ecology of Reserved Humid Tropical Vegetation, Kuching.

Licker, M.D. 2003. Dictionary of bioscience $2^{\text {nd }}$ ed. McGraw-Hill, New York.

Mogea, J.P., Gandawidjaja, D., Wiriadinata, H., Nasution, R.E., Irawati. 2001. Tumbuhan langka Indonesia. Pusat Penelitian dan Pengembangan Biologi - LIPI, Bogor, Indonesia.

Mulder, V., Heri, V., Wickman, T. 2000. Traditional honey and wax collection with Apis dorsata in upper Kapuas Lake region, West Kalimantan. Borneo Research Bulletin 15: 46.

Pearce, C.E.M., Pearce, F.M. 2010. Oceanic migration: Paths, sequence, timing and range of prehistoric migration in the Pacific and Indian Oceans. Springer, New York.

Rahayu, M., Rugayah, Praptiwi, Hamzah. 2002. Keanekaragaman pemanfaatan tumbuhan obat oleh masyarakat Suku Sasak di Taman Nasional Gunung Rinjani, Lombok NTB. Prosiding Simposium Nasional II Tumbuhan Obat dan Aromatik. Bogor, 116$123 \mathrm{p}$.

Rahayu, M., Sunarti, S., Keim, A.P. 2008. Kajian etnobotani pandan samak (Pandanus odoratissimus L.f.): Pemanfaatannya dan peranannya dalam usaha menunjang penghasilan keluarga di Ujung Kulon - Banten. Biodiversitas 9(4): 310-314.

Rensch, B. 1930. Eine biologische reise nach den Kleinen Sunda-Inseln. Gebrüder Borntraeger, Berlin.

Susiarti, S., Rahayu, M. 2010. Kajian etnobotani pandan samak (Pandanus tectorius Sol.) di Kabupaten Tasikmalaya, Jawa Barat. Berita Biologi 10 (1): 113-121. 
Susiarti, S., Polosakan, R., Rahayu, M. 2011. Ekstraktivisme madu alam dan aspek sosial ekonominya di kawasan konservasi PT WKS, Jambi. Valuasi Hasil Hutan Bukan Kayu Kawasan Lindung PT Wira Karya Sakti, Jambi, MAB-UNESCO LIPI dan Sinarmas Forestry, 180-188 p.

Trivedi, P.C., Nehra, S. 2009. Potential medicinal plants: Botany, medicinal uses and chemical constituents. In Trivedi, P.C. (eds.). Medicinal plants: Utilisation and conservation. $2^{\text {nd }}$ edition Aavishkar Publishing, Jaipur, 405-424 p. 